AÜIFD Cilt XLIII (2002) Sayı 2 s. 521-528

\title{
Kitap Tanıtımı
}

\author{
Dr. Mustafa Hi̇zMETLi
}

es-Sicillu'l-İlmî li Nedveti'l-Endelüs, Editör Dr. Abdullah b. Ali ezZeydan, Neşr. Mektebetü'l-Melik Abdülaziz el-Âmme, V. Cilt, Riyad, 1417/ 1996.

İslâm kültür ve medeniyeti konusunda takdire değer gelişmelerden biri de konuyla ilgili çalışmaların Ortadoğu'ya münhasır olmaktan çıkarak yerini daha evrensel bir bakış ve anlayışa bırakmasıdır. Bu önemli anlayış değişikliğinin sonuçlarnndan biri de Endülüs tarih, kültür ve medeniyetinin çeşitli araştırma ve incelemelere konu olması, düzenlenen uluslararası sempozyumlarda gündeme gelmesi ve tartışılmaya başlamasıdır. Bizim tanıtmayı hedeflediğimiz eser de bu maksatla düzenlenen $X$. Enduilüs Sempozyumu'nda sunulan tebliğlerden oluşmaktadır.

Riyad'da 15-19.5.1414/30.10.-03.11-1993 tarihleri arasında düzenlenen sempozyumun konusu "Endülüs, Tarih ve Uygarlık" olarak belirlenmiştir. Organizasyonu kral Abdülaziz Halk Kütüphanesi tarafından gerçekleştirilen sempozyumu Prens Abdullah b. Abdülaziz özel olarak desteklemiştir. Sempozyum dünyaca meşhur Endülüs uzmanlan ve Suudî araştırmacıların katılımıyla gerçekleştirilmiştir. Tebliğler beş ana başlık alında tasnif edilmiştir. Daha sonra sempozyum tebliğ metinlerinin basımında da bu başlıklar esas alınmış ve metinler, her bir başlık ayrı bir cilt olmak üzere, beş cilt halinde yayımlanmıştır. Tebliğlerin başında İngilizce ve Arapça özetleri de yer almaktadır. 
Birinci cildin konusu tarih ve felsefedir. Bu bölümde on üç Arapça, beş Ingilizce ve iki İspanyolca tebliğ yer almaktadır. İspanyolca tebliğlerin Arapça çevirilerine de yer verilmiştir. $(473+120$ sayfa).

Bu bölümün "Merkeziyyetü't-Tecribeti'l-Endelüsiyye ve Eseruhâ fi'lVa'yi'l-Tarihi'l-Arabîyyi'l İslâmî" (Endülüs Tecrübesinin Merkeziliği ve Arap-İslam Tarih Bilinci Üzerindeki Etkisi) isimli ilk tebliğinde Nureddin esSağîr, Endülüs tecrübesinin Arap-İslâm tarihindeki derin etkisini olumlu ve olumsuz yönleriyle ortaya koymaya çalışmaktadır. Bu çerçevede Endülüs'teki birikimin insanlık medeniyetine katkısı ve Batı medeniyetinin oluşumundaki önemli rolü de ele alınmaktadır. Tebliğ, ayrıca Endülüs tecrübesinin yeni bir uygarlık inşasına koyulan Arap-İslâm ümmeti üzerindeki etkisini de ortaya koymayı hedeflemektedir. Bu katkılar; din (s.16), siyaset (s.19), sosyal hayat (s.21), ekonomik hayat (s.21), ilmî hayat (s.22), musikî (s.24), edebiyat (s.25) ve miman̂ (s.26) başlıklan altında incelenmektedir.

"Tarihu Medineti Turtuşa el-Islâmiyye ve Hadâretühâ fî Asrı Düveylâti't-Tavâif" (Mülûku't-Tavâif Döneminde Müslüman Turtuşa Şehrinin Tarihi ve Medeniyeti), bu bölümde yer alan diğer bir önemli tebliğdir. Kemal es-Seyyid Ebû Mustafa'nın hazırladığı tebliğde, Endülüs şehirlerinden Turtuşa'nın tarihi ele alınmaktadır. Kurtuba Emevî halifeliğinin çöküşü ile başlayan mülûku't-tavâif döneminde el-Mansur el-Mirînnin sakâlibesinin idaresinde bağımsız bir devlet haline gelen Turtuşa, bu egemenliğini, şehrin Sarakusta'ya hükmeden Hûdîlerin eline geçmesine (452-53/1060-1061) kadar devam ettirdi. Turtuşa, 545/1447'de Barselona kralı IV. Ramon'un istilasına kadar ise Murabıtların nüfuz bölgesi içerisinde yer aldı. Tebliğci, Turtuşa'daki İslâm medeniyetinin çeşitli yönlerini incelerken şu konulara da yer vermektedir: Şehir planı (s. 180), pazarlar (s.184), para (s.188); ayrica sosyal, ekonomik ve entelektiuel faaliyetler (s.186-189). (S. 161-199)

Üzerinde durulan bölümün dikkat çekici tebliğlerinden biri de Mustafa Ibrahim Hüseyin'in kaleme aldığı "Masâdıru Lisaniddin İbni'l-Hatîb fi Kitabihi 'el-İhâta fi Ahbâri Gtrnata" (Lisanüddin İbnu'l-Hatîb'in el-İhâta fi Ahbâri Gırnata Adlı Eserinin Kaynakları), başlıklı çalışmasıdır. Araştırma, Endülüs'ün yetiştirdiği önemli şahsiyetlerden biri olan devlet adamı ve âlim İbnu'l-Hatîb'in meşhur eseri el-İhâta fi Ahbâri Gtrnata'yı telifi sırasında faydalandığı kaynakları incelemektedir. Bu kaynaklar a) kitaplar (s.336), b) rivayetler (s.362), c) müdevvenât (arşiv kayıtlan) (s.364), d) müşahede ve muâsara (tanıklık ve çağdaşık) (s. 370), e) yazışmalar (s.372), başlıkları altında incelenmektedir (s.321-377). 
Bu bölümün dikkate değer tebliğlerinden biri de, "Ehemmiyetü'lFetâvâ'ı el-Fıkhiyye fî Keşfi Vekâiı't-Tecribeti'l-Endelüsiyye" (Endülüs Tecrübesinin Mahiyetini Anlamada Fetva Metinlerinin Önemi) başlıklı çalışmadır. Ahmed el-Yusufî Şuayb bu tebliğinde, en eski İslâm fetva kitaplanndan biri olarak kabul edilen Nevâzilu Ibni'l-Hâcc'a dayanarak Endülüs medeniyetinin özellikle ekonomik ve sosyal hayatla ilgili tezahürlerini ortaya koymaktadır. Araştırmanın malzemesini, VI/XII. yüzyıl Endülüs ekonomik ve sosyal hayatına $1 s ̧ \mathrm{k}$ tutan fetva metinleri oluşturmaktadır. Çalışmada ayrıca, söz konusu dönemde, Endülüslü fakihler ve müftilerin çözmeye çalıştıklanı problemlere ve Endülüs günlük hayatıyla ilgili tezahürlere de yer verilmektedir (S. 381-401).

Birinci ciltte yer alan diğer tebliğleri şu şekilde sıralamamız mümkündür: "et-Turâsi'l-Endelüsî ve Mes'eletü'l-Vahdet" (Endülüs Kültürü̈ ve Vahdet Meselesi), "Nüfûzu's-Sakâlibe fi'l-Endelüs fi Asrı'l-İmâreti ve'lHilafeti 755-976" (Emirlik ve Halifelik Dönemlerinde Endülüs'te Sakâlibe Nüfûzu 755-976), "Eserü Fitneti Kurtuba" (Kurtuba Fitnesinin Etkisi), "Cevânib min Tarihi Ehli'z-Zimmeti fi'l-Endelüsi'l-İ́slamiyyeti" (Endülüs'te Zımmîlerin Tarihinden Kesitler), "el-Murabitûn ve Siyâsetu't-Tesâmuh me'a Nasârâ'l-Endelüs" (Murabıtlar ve Endülüs Hristiyanlarına Karşı Müsâmaha Siyaseti), "el-Büyûtâtü'l-Endelüsiyyetü (Endülüslü Seçkin Aileler), "Benû sım: Usretün Endelüsiyyetün min el-Ulemâi ve's-Siyasiyyîn ve Eserühüm fi Gırnata fi Asrn Benî'l-Ahmer 1238-1492" (Benî Asım: Endülüslü Âlimler ve Siyasetçiler Yetiştiren Bir Ailenin Benî Ahmer Dönemi Gırnata'sındaki Etkisi (1238-1492), "Amelü't-Terâcimi'r-Rıcâl fi'l-Endelüs" (Endülüs'te Biyografi Çalışmaları), "el-Endelüs Beyne'l-İhtibâr ve'l-'İtibâr" (İbret Alma ve Tecrübe Kazanma Arasında Endülüs), "The Treaties of Capitulation and Patterns of Arab Settlement in al-Andalus" (Barış Antlaşmaları ve Müslümanların Endülüs'te Yerleşmesi, "Sevretü'l-Berber fi Şimâli İfrîkiya 122/740 ve In'ıkâsâtuhâ ale'-l-Endelüs" (Kuzey Afrika'daki Berberi İsyant (122/740) ve Endülüs'teki Yansımaları), "Madrid: el-Kal'atu'ş-Şehîretü" (Madrid: Meşhur Kale), "Some Reflections on The End of Islamic Granada" (Müslüman Gırnata'nın Sonuna İlişkin Bazı Düşünceler), "Before and After al-Andalus: Two Cultural Transitions" (Önce ve Sonrastyla Endülüs: Íki Kültürel Geçiş), "The Recovery of al-Andalus in Blas Infante's Political Theory" (Blas Infante'nin Politik Teorisinde Endiulüs Mirasının Yeniden Keşfi).

İkinci cildin konusu Moriskolar, eserler (kitabiyât), oryantalistlerin çalışmaları, coğrafya ve seyahatlerdir. Bu ciltte on beşi Arapça, biri İspanyolca olmak üzere toplam on altı tebliğ bulunmaktadır. ( $516+17$ sayfa). 
Bu bölümün önemli tebliğlerinden biri, "Alâkâtu'l-Moriskiyyîn bi'lArâdî'l-Arabiyyeti'l-Mükerremeti" (Moriskoların Kutsal Arap Beldeleriyle Iliş̧kileri) başlıklı çalışmadır. Tarık Muhammed Hıdr bu araştırmasında, yayımlanmamış Morisko el yazmalarına dayanarak Moriskoların kutsal Arap beldeleri ile ilişkilerini inceleme konusu yapmaktadır. Bu ilişkiler fikrî planda ve rihle edebiyatında tasvir edilenler olmak üzere iki kısımda incelenmektedir. Sonuçta bu araştırma, Morisko Arapça el yazmalarıyla ilgili Arapça araştırmaların yetersizliğine dikkati çekmektedir. Araştırmanın diğer önemli bir sonucu da Endülüs tarihinin yeniden yazılmasını gerektirecek niteliktedir. Çünkü yazara göre, bu yazmalar, Endülüs edebiyatının Gırnata'nın düşüşüyle bitmediğini; Moriskolar için 1609 yılında çıarılan nihâ̂ sürgün kararına kadar eser vermeye devam ettiğini göstermektedir (s. 41-66).

Söz konusu bölümde yer alan diğer bir tebliğ ise, "el-Husûsiyetü'lEndelüsiyye ve Usûluhâ'l Coğrafiyyeti" (Endülüs'ün Farklılı̆̆ı ve Bunun Coğrafi Temelleri) başlıklı çalışmadır. Ubade Abdurrahman Rıza Kuheyla, bu önemli tebliğinde, Endülüs'ün temel niteliklerinin oluşmasında coğrafî faktörlerin rolünü incelemiştir. Bu coğrafî yapının bir sonucu olarak, şehirlerin sayısı çoğalmış, kabile asabiyetinin yerini şehir asabiyeti almış, her şehrin sağlam bir kalesinin olması gerekmiş, yerel güçlerin merkezî otoriteye direnişi kolaylaşmıştır. Ayrıca bu coğrafî yapı, erken dönemde başlayan Hristiyan direnişini kolaylaştırdığı gibi, mülûkü't-tavâif' in ortaya çıkmasına ve yaşamasına da zemin hazırlamı̧̧tır. (S. 427-473).

Ikinci ciltte yer alan diğer tebliğler şunlardır: "et-Tecribetü'lEndelüsiyyetü'l-Moriskiyyetü" (Endülüs Morisko Tecrübesi), "Evdâu'lCâliyeti'l-İslamiyyeti bi'l-Burtuğal ve Zurûfu İndisârihâ" (Portekiz'deki Müslüman Azınlığın Durumu ve Kayboluş Şartları 1246-1496), "edDevletü'l-Osmaniyyetui ve Me'sâtü'l-Müslimîne fi'l-Endelüs" (Osmanlı Devleti ve Müslümanların Endülüs'teki Dramı 1486-1609), "Tardu'lMüslimîn mine'l-Endelüs -Merâhiluhû, Sâruhû ve Netâicihû" (Müslümanların Endülüs'ten Sürülmesi -Aşamaları, Etkileri ve Sonuçları-), "el-Moriskiyyûn fi'l-Fikri't-Tarihî'l-Esbânî" (İspanyol Tarihçiliğinde Moriskolar), "et-Tecribetü'l-Endelüsiyyetü fi Dirâsâti'l-Müsteşrikîn" (Müsteşriklerin Araştırmalarında Endülüs Tecrübesi), "el-Müsteşrikûn ve Tarihu'l-Müslimîn fi'l-Endelüs" (Müsteşrikler ve Müslümanların Endülüs'teki Tarihi), "et-Turâsü'l-Islâmî'l-Endelüsî fi Mîzâni'l-İstişrâki'lEsbânîyyi'l-Muâsır" (Çağdaş İspanyol Müsteşriklere göre Endülüs İslâm Mirast), "el-Fikrü'l-İslâmî bi'l-Endelüs fi Tasavvurâti'l-İstişrâki'lEsbânîyyi'l-Hadîs" (Modern Isspanyol Şarkiyatçılı̆̆ının Tasavvurlarına Göre 
Endülüs İslâm Düşüncesi), "el-İtticâhâtü'l-Esbâniyyetü Hıyâle'l-Hikbeti'lEndelüsiyye" (İspanyol Tarihçilerin Endülüs'teki Müslüman Dönemine İlişkin Eğilimleri), "el-Mu'cemü'l-Cuğrafî fi'l-Endelüs" (Endülüs'te Coğrafi Sözlük Çalışmaları), "Rahelâtu'l-Endelüsiyyîn ile'l-Haremeyn" (Endülüslülerin Haremeyn Bölgesine Seyahatleri), "Rahelâtu Arabi'lEndelüs ve Şimâli İfrikiyâ ilâ Cüzüri'l-Atlasî ve'l-Amerikiyîn" (Endülüs ve Kuzey Afrika Araplarının Atlantik ve Amerika Adalarina Seyahatleri), "elMoriskiyyûn fî Kurtuba" (Kurtuba'da Moriskolar).

III. Cildin konu başlığı medeniyet, bayındırlık-mimarî ve bilimteknoloji şeklindedir. $\mathrm{Bu}$ bölümde on Arap̧̧a, dört İngilizce ve bir İspanyolca tebliğ yer almaktadır. (284+161 sayfa).

$\mathrm{Bu}$ bölümdeki tebliğler içerisinde dikkati çeken Dr. Muhammed Abdullah el-Hammad'ın "et-Tahtîtü'l-Umranî li-Müdüni'l-Endelüs elİslâmiyyeti" (Endülüs Kentlerinde Şehircilik) isimli çalışmasıdır. Araştırma Íspanyol şehirlerinin fetihten sonra, birer İslâm şehri karakteri kazanması olgusunu Kurtuba, Meriye ve Gırnata örneğinde ele almaktadır. İspanyol şehirlerinin doğudaki Müslüman şehirlerinin özelliklerini de birleştiren birer İslâm şehri karakterini kazanmalarını ve Endülüs aile ve kültür yapısını bünyelerinde kaynaştırmalarını inceleyen çalışma, tek bir çevrede toplumsal çoğulculuğun korunmasını sağlayan faktörleri de değerlendirmektedir. Çalışmadaki önemli konu başlıkları şunlardır: Kurtuba, Meriye ve Gırnata şehirlerinin planı ve mimarî yapısı(s.152), şehrin içi( cami, pazarlar, hamamlar, iskan ve nüfus s.158-160), şehrin dışı (s.161) su kaynaklan ve su temini (s.162), Endülüs şehirlerinin mimarî özellikleri (s.163), şehirdeki ilmî, fikrî hayat (s.167), şehrin yönetimi (s.170) (s. 145-175).

$\mathrm{Bu}$ ciltte yer alan diğer tebliğler şunlardır: "Menziletü'l-İlmi ve'tTa'lîmi bi'l-Endelüs min Hılâli Risâletu Merâtibi'l-Ulûm li İbn Hazm" (İbn Hazm'ın Merâtibu'l-Ulûm Risâlesine Göre Endülüs'te Ilmin ve Eğitimin Konumu), "er-Riyâziyâtu fi'l-Endelüs" (Endülüs'te Matematik), "Müsâhemetü Riyâziyyi'l-Endelüs fi'l-Hayati'l-İlmiyyeti bi Ifrîkiyye H1lale'l-Kurûnu'l-Vustâ" (Endülïislü Matematikçilerin Ortaçă̆'da Afrika'daki İlmî Hayata Katkıst), "et-Tecribetü'l-Endelüsiyyetü bi'lCezayir" (Cezayir'de Endülüs Tecrübesi), "İntikâlü'l-Ulûmi'l-Arabiyyeti mine'ş-Şark ile'l-Ğarb ve Te'sîrühâ fi Avrubba" (Arap ilimlerinin Doğu'dan Batı'ya Geçişi ve Avrupa Üzerindeki Etkisi), "Devrü Medreseti't-Tercemeti bi Tuleytula fi Nakli'l-Ulûmi'l-Arabiyyeti ila Avruba" (Tuleytula Tercüme Okulunun Arap Illimlerinin Avrupa'ya Aktarllmastndaki Rolü), "Eserü'lCâmii'l-Emevî bi Dimeşk alâ İmâreti'l-Mescidi'l-Câmii bi Kurtuba" (Şam'daki Emevî Camii'nin Kurtuba Ulu Camii Üzerindeki Mimarî Etkisi), 
"Urefâ el-Bennâ fi'l-Mağrib ve'l-Endelüs ve Ehemmü A'mâlihimi'lMi'mâriyyeti" (Mağrib ve Endülüs'te Mimarlar ve Önemli Mimarî Çalışmaları), "al-Andalus as a Cultural Bridge Between East and West" (Doğu ile Batı Arasında Kültürel Bir Köprü Olarak Endülüs), "Hydnc Aspects in Islamic City Planning" (İslâm Şehir Planlamasında Su Yolları), "el-Eb'âdü'l-Hafiyyetui li'l-Miyâh fi'l-Hamrâ/Mystıcal Dımensions of Water in The Alhambra" (el-Hamra Sarayındaki Suların Gizemli Yönleri), "The Network of Irrigation Ditches in The Alpujarra of Granada" (Gtrnata Alpujarra'da Tarımsal Sulama Kanalları A $\breve{g} l$ ), "ez-Zücâcü'l-İslâmî fi Mürsiye" (Mürsiye'de İslâm Cam Sanayii).

IV. Cildin konusunu dil ve edebiyatla ilgili çalışmalar oluşturmaktadır. $\mathrm{Bu}$ ciltte bu iki konuyla ilgili on sekiz Arapça ve bir İngilizce tebliğ bulunmaktadır. ( $665+18$ sayfa).

$\mathrm{Bu}$ bölümün dikkat çeken tebliğlerinden biri Abdullah b. Ali b. Sekfân'ın "Zâhiretü'l-İntimâi fì'l-Edebi'l-Endelüsî" (Endülüs Edebiyatında Mensubiyet Olgusu) isimli çalışmasıdır. Bu çalışmada yazar, tarih ve edebiyat alanındaki belli başlı Endülüs ve Mağrib kaynaklarını incelemek suretiyle Endülüs düşünce ve edebiyatının Doğu'nun taklidi olduğu iddiasını reddetmektedir. İncelemeye konu olan eserler şunlardır: İbn Hayyân, elMuktebes; Ibn Hakân, el-Kalâid ve el-Matmah; İbn Bessam, ez-Zahire; İbn İzârî, el-Beyan; İbn Saîd, el-Muğrib; İbnu'l-Ebbâr, el-Hulle; el-Makkarî, Nefhu't-Tib. Sonuç olarak yazar, "bu eserler her ne kadar Doğu'dan alınan ilhamla yazılmışlarsa da kimlik ve karakter bakımından onlardan tamamen farklıdırlar" tezini savunmaktadır.(s.145-180).

Bu bölümde yer alan bir başka ilgi çekici tebliğ, "el-Endelüs fi'lEdebi't-Türkiyyi'l el-Hadîs" (Çağdaş Türk Edebiyatında Endülüs)'tür. Muhammed Abdullatif Heridî bu çalışmasında, Endülüs'ün modern Türk edebiyatına ilham kaynağı olmasını Tanzimat dönemi Türk edebiyatçılarının eserlerinden yola çıkarak incelemektedir. Çalışmada eserleri incelenen Tanzimat dönemi edebiyatçılan Şemseddin Sami (s.335), Abdulhak Hamit Tarhan (s. 336) ve Muallim Naci (s.339)'dir. Yazara göre, Endülüs'ün modern Türk edebiyatına ilham vermesinin temelinde Endülüs tarihi ile Türklerin Balkanlar ve Doğu Avrupa'daki tarihlerinin benzerliği yatmaktadır. Yazar, Türklerdeki bu duyarlıktan yola çıkarak Endülüs'ün bütün Islâm ümmetinin vicdanında var olmaya devam ettiğini dile getirmektedir.

$\mathrm{Bu}$ ciltte yer alan diğer tebliğlerin isimlerini şöylece sıralamamız mümkündür: "İshâmatu ve Cühûdu'l-Lugaviyyîn el-Endelüs fi Refdi'sSekâfeti'l-Arabiyyeti ve'l-İslâmiyyeti" (Endülüslü Dilcilerin Arap ve İslâm 
Kültürünü Güçlendirmedeki Çaba ve Katkılart), "Me'acimü'l-Ef'al Cühûdun Endelüsiyyetün Râidetün ve Alâmetün Bârizetün fi Sarhi's-Sekâfeti'lEndelüsiyyeti" (Muhteşem Endülüs Kültürrünün İnşasinda Endülüslü Öncü Çabalar: Kitabu'l-Ef'aller), "Ziyâdâtun lem Tünşer fi Kitabı Islâhı Lahnı'lÂmmeti bi'l-Endelüs li Ebî Bekr Muhammed b. Hasen ez-Zebîdî elİşbilî" (ez-Zebîdî'nin Islahu Lahni'l-mme bi'l-Endelüs Adlı Eserine Yapılan Neşredilmemiş Zeyiller), "Udebâü'l-Endelüs, İshâmâtühüm ve Te'sîrühüm fi'l-Hareketi'l-Edebiyyeti'l-Arabiyyeti" (Endülüs Edebiyatçılarının Arap Edebî Hareketine Katkıları ve Etkisi), "el-Hayâlü'l-Kasasî fi't-Tecribeti'lEndelüsiyyeti Beyne'l-Muhâkâti ve'l-İbdâ'" (Endülüs Tecrübesinde Taklit ve Yaratıcılık Arasında Hikayede Hayal Gücü), "Sûretii'l-Endelüs fi Rivâyâti Corci Zeydan" (Corci Zeydan'ın Rivayetlerindeki Endülüs İmajı), "Fantazya't-Tarih, er-Remzü ve'l-Vâki' fi'l-Hâleti'l-Endelüsiyyeti" (Tarih Fantazisi, Endülüsün Durumu Konusunda Sembol ve Gerçek), "Abbas b. Firnas" (Abbas b. Firnas), Sükûtu'l-Endelüs fi'l-Edebi'l-Urdî" (Urdu Edebiyatında Endüliü'ün Düşüşü), "Necd ve'l-Hicâz fi'z-Zâkireti'şŞi'riyyeti'l-Endelüsiyyeti" (Endülüs Şiirinde Necd ve Hicaz), "elMüveşşahu'l-Endelüîi ve'l-Maşrikî" (Endülüs ve Doğu Müveşşahl), "eşŞi' rü'l-Endelüsî ve Şi'rü't-Trûbâdur" (Endülüs Şiiri ve Troubadour Şiiri), "Devâvînü'l-Karni's-Sâmin el-Hicrî bi'l-Endelüs" (VIII. Hicrî Astrda Endülüs'te Divanlar), "el-Firdevsü'l-Mefkûd" (Yitik Cennet), "ed-Dersü'nNahvî fi'l-Endelüs fi'l-Karni'l-Hamisi'l-Hicrî" (Hicrî V. Asirda Endülüs'te Gramer Çalışmaları), "el-Mütenebbî fi Zahireti İbn Bessâm el-Endelüsî" (Endülüslü İbn Bessam'in ez-Zahire'sinde el-Mütenebbî), "History of the Aljamiado Studies in XIX. Century" (XIX. Yüzyllda Aljamiado Araştırmalarının Tarihi).

V. Cildin konu başlığı dinî ilimlerdir. Bu bölümde konuyla ilgili yedi Arapça tebliğ metni yer almaktadır ( 359 sayfa). Bu cildin sonunda aynca, $X$. Endülüs Sempozyumu'na katılan bilim adamları ve tebliğlerin isimlerinin bulunduğu iki ayrı fihrist yer almaktadır.

$\mathrm{Bu}$ bölümde yer alan tebliğlerin bizce en dikkate değer olanı "Menhecu'l-Medreseti'l-Endelüsiyyeti fi't-Tefsîr (Tefsirde Endülüs Okulunun Metodu) adlı çalışmadır. Fahd b. Abdurrahman b. Süleyman erRûmî tebliğinde Endülüs tefsir okulu mensuplarının tefsir metotlarını, akide, fıkıh, hadis ve lugat alanındaki özelliklerini incelemektedir. Yazar tebliğinde Bakî b. Mahled, Ebû Bekr İbnư'l-Arabî, İbn Atiyye, Ebû Abdillah el-Kurtubî, İbn Cuzey el-Kelbî el-Gırnatî ve Ebû Hayyan örneğinde Endülüslü tefsircilerin Kur'an ilimleri ve özellikle nâsihmensuh, esbâb-ı nüzul, icâzu'l-Kur'an gibi ilimleri Kur'an ayetlerinin 
incelenmesinde kullanma usulleri gibi konulardaki ayırıcı vasıflarını da incelemektedir.

"et-Tefsîr ve Ulûmü'l-Kur'an bi'l-Garbi'l-İslâmî" (Batı İslâm Dünyasında Tefsir ve Kur'an Illimleri), "el-Endelüsiyyûn ve İstihdâsü Masdarin Teşri'iyyin Cedîdin" (Endülüslüler ve Yeni Bir Teşrî Kaynăğ Oluşturulmast), "et-Ta'dîl'ınde Ebî Bekr İbnü'l-Arabî" (Ebû Bekr İbnü'l-Arabî'ye Göre Adalet Kavramu), "İshâmu Ulemâi'l-Endelüs fi Te'sîli'l-Fikri'l-İslâmî" (Endülüs Ulemâsının İslâm Düşüncesinin Temellendirilmesine Katkıları), "İbnü'l-Hâc et-Tucîbî el-Kurtubî ve Mesâili Buyû'ihi fi Mi'yâri'l-Venşirîsî" (Kurtubalı Íbnu'l-Hac et-Tucîbî̀ ve elVenşirisî'nin el-Mi'yar'ındaki 'Buyû' ile İlgili Meseleler) ve "Nâzıru'lAhbâs fi'l-Endelüs ve'l-Mağrib" (Endülüs ve Mağrib'de Nâzıru'l-Ahbas) ise, bu bölümde yer alan diğer tebliğlerdir.

Gerek seçip tanıttığımız tebliğlerin muhtevası, gerekse diğer tebliğlerin başlıklan sempozyumun gün ışığına çıkardığı birikimin büyüklü̆üünü göstermek için yeterlidir. Endülüs medeniyetinin mirası değerlendirilirken müsteşriklernn çalışmalanının göz ardı edilmemesi hem eleştirel bakışa verilen önemi, hem de önyargılı oryantalist tavrı değerlendirmeye yönelik bir çabayı temsil etmektedir. Burada sempozyuma katılan bilim adamlarının seçimi konusunda bir iki konuyu dile getirmek istiyoruz. Uluslararası nitelikteki böyle bir sempozyuma İspanyol Pedro Chalmeta ve Misırlı Mahmud Ali Mekkî gibi uzmanların katılmamış olması bir eksiklik sayılmalıdır. Çünkü İspanyol araştırmacılanı Endülüs mirasının kalıntılarına sahip olmak gibi bir avantaja sahip olduğu bir gerçektir. Mısırlı araştırmacılar ise ilk dönemden itibaren Endülüs'e gösterdikleri ilgi dolayısıyla hakhı bir ün kazanmışlardır. Özellikle es-Seyyid Abdulaziz Salim ve Mahmud Ali Mekkî bu konuda unutulmaması gereken iki isimdir. Ayrica bazı konuların ancak o ülke ilim adamlan tarafından işlendiği takdirde daha objektif bir nitelik kazanacağı unutulmamalıdır. Sözgelimi, Osmanlı Devleti ile Endülüs Müslümanlannın ilişkileri konusunu Türkiyeli bir ilim adamı ele alsa daha sağlıklı olurdu diye düşünmekteyiz.

Bütün eleştirilecek yönlerine rağmen sempozyumun bir çok alanda önemli katkıları olmuştur. Sempozyumun Gırnata'nın düşüşünün 500. Yıldönümü sonrasına rastlamış olması çok önemlidir. Bilindiği gibi, aynı tarih Türkiye dahil pek çok ülkede, Yahudi sürgününün 500. Yildönümü olarak kutlanmıştı. Müslüman ülkelerin geleceklerini tasarlarken geçmiş mirastan yararlanmayı ihmal etmeme kararlılıklarını yansıtması bakımından Endülüs Sempozyumu'nu yenileri izlemeli ve Müslüman mirasına yönelik ilgi Endülüs'e münhasır kalmamalıdır. 